\title{
CHANGES IN THE LEIDENFROST TRANSITION POINT DURING THE EVAPORATION OF WATER AND N-HEPTANE DROPLETS ON HOT, POROUS STAINLESS STEEL SURFACES
}

\author{
N. Lipson \\ Dept. of Mechanical \& Industrial Engineering \\ University of Toronto \\ Toronto, Canada
}

\author{
S. Chandra \\ Dept. of Mechanical \& Industrial Engineering \\ University of Toronto \\ Toronto, Canada
}

\section{INTRODUCTION}

\begin{abstract}
The impact and evaporation of droplets impinging on a heated porous substrate is relevant to applications such as fire suppression by sprinkler systems, spray cooling of heated surfaces, and the deposition of fuel droplets on combustor walls. Design involving these sub systems requires an understanding of the heat and mass transfer between the droplet and porous surface. An experimental study was done in which pure water and $n$-heptane droplets were deposited onto porous, stainless steel surfaces made from sintered powders with varying pore size $(5 \mu \mathrm{m}$ and $100 \mu \mathrm{m})$. n-Heptane was chosen to compare the effects of surface tension on the evaporation process. Initial surface temperatures were varied from $60^{\circ} \mathrm{C}$ to $300^{\circ} \mathrm{C}$. Results were compared with those for droplet evaporation on a solid, impermeable stainless steel surface. On porous surfaces, it is difficult to determine when a droplet has completely evaporated from video images, since liquid penetrates into the surface pores. At low wall temperatures $\left(60^{\circ} \mathrm{C}\right.$ to $\left.120^{\circ} \mathrm{C}\right)$, droplet evaporation was measured by placing the heated surface on a digital scale and recording the weight decrease as a function of time. At high wall temperatures (above $120^{\circ} \mathrm{C}$ ), video techniques were employed to capture evaporation times. At high wall temperatures, the porous surfaces were the most effective at vaporizing both the pure water, and n-heptane droplets, resulting in the lowest evaporation times. At low wall temperatures the porous surfaces became less effective at transferring heat to both the water and n-heptane. For n-heptane the evaporation times increased on the porous surfaces as compared to the impermeable surface. Similar results could be seen with the water on the $100 \mu \mathrm{m}$ surface. The Leidenfrost transition point was shown to increase with porosity. Droplet levitation was not achieved with the water on the porous surfaces, however due to the lower heat of vaporization of n-heptane it was achieved on the $5 \mu \mathrm{m}$ and $100 \mu \mathrm{m}$ substrates at surface temperatures of $225^{\circ} \mathrm{C}$ and $285^{\circ} \mathrm{C}$ respectively.
\end{abstract}

Keywords; Porous media, Evaporation, Stainless steel, Water, $n$ Heptane, Pore size, Leidenfrost point
Liquid droplet impact on hot porous surfaces is studied due to its significance in a wide variety of spray cooling applications. These include, cooling of reactors in nuclear power plants; fire suppression by sprinkler systems; and the deposition of fuel droplets on combustion chamber walls. In the fire extinguishment process, water can be used to both extinguish flames, and prevent the flame spread by cooling surfaces that have not yet been ignited. However, the use of large amounts of water can cause secondary fire damage encouraging research into this area to reduce the amount of water used. As fires can involve the burning of porous materials (e.g. wood, fabrics, papers), understanding the thermal effects of droplet impingement on hot porous surfaces will assist in predicting the quantity of water needed for sufficient cooling of the surface while minimizing secondary damage. In addition to fire suppression systems, the evaporation of fuel droplets on heated surfaces is of critical importance in the design of combustion devices. Optimizing droplet evaporation times is important in ensuring improved combustion efficiencies, and reducing gaseous emissions during the combustion process.

The total evaporation time of a droplet is dependent on several key parameters. Reference [1] stated that the heat transfer rate to the droplet is governed by the fluid and solid thermal properties, as well as the surface roughness and temperature. The surface temperature was described as the most significant parameter as it is used to define the heat transfer regime the droplet resides in (i.e. single phase evaporation, nucleate boiling, and film boiling). However, porous surfaces substantially alter the impact dynamics and heat transfer to the droplet. A droplet impinged on a porous substrate will not only spread over the surface, but penetrate into the surface pores. This pore penetration can enhance the heat transfer to the fluid and is known to depend on the properties of both the liquid and the porous substrate (i.e. pore size, porosity, wettability) [2]. The critical parameter influencing the impact behavior of the droplet is the Weber number. The Weber number, We, is defined as the ratio of the droplets inertial to surface tension forces. 


$$
W \mathrm{e}=\frac{\rho_{f} u_{o}^{2} d_{o}}{\sigma}
$$

The present work reports the results of an experimental study involving the evaporation of pure water and n-heptane $\left(\mathrm{C}_{7} \mathrm{H}_{16}\right)$ droplets deposited on hot porous substrates with different pore sizes, and varying surface temperatures. n-Heptane was chosen since it has lower surface tension and higher wettability compared to water and penetrated more easily into surface pores. A digital scale was the measurement technique used at low wall temperatures, where the evaporation times were captured from weight decrease as a function of time plots. There were two main objectives for this work: (1) measure droplet evaporation times using a weight-time approach at low wall temperatures to remove the uncertainty associated when using imaging techniques, and (2) to compare the effects of fluid surface tension on the impact and evaporation of a droplet when impinged on a porous substrate with different surface temperatures.

\section{EXPERIMENTAL METHOD AND CONDITIONS}

Fig. 1 shows a schematic of the experimental setup employed to observe the droplet evaporation of a pure water and n-heptane droplet on a heated sintered 316 stainless steel porous substrate (5 $\mu \mathrm{m}$ and $100 \mu \mathrm{m}$ average pore size, see Fig. 2). The results were compared with those for droplet evaporation on a solid, impermeable 316 stainless steel substrate. The arithmetic average surface roughness Ra for the impermeable, $5 \mu \mathrm{m}$ and $100 \mu \mathrm{m}$ surfaces are $0.100 \pm 0.004 \mu \mathrm{m}, 4.7 \pm 0.1 \mu \mathrm{m}$ and 12.2 $\pm 1.6 \mu \mathrm{m}$ respectively. All surfaces were square, $45 \mathrm{~mm}$ x $45 \mathrm{~mm}$ in size and $1.5 \mathrm{~mm}$ thick. Surface temperatures were varied from $60^{\circ} \mathrm{C}$ to $300^{\circ} \mathrm{C}$. A gauge $24 \mathrm{~K}$-type thermocouple was fixed using Omega $\mathrm{CC}$ high temperature cement to the surface of each of the substrates. The surface temperatures were monitored using a wireless thermocouple connector (MWTC-D-K-915, Omega Engineering, Laval, Quebec, Canada) and droplet evaporation was experimentally observed in the evaporative, nucleate boiling, and film boiling regimes.

Using a syringe pump (NE-1000, New Era Pump Systems, Farmingdale, New York, United States), $2.5 \mathrm{~mm}$ diameter droplets were formed with a gauge 26 blunt hypodermic needle for pure water, and a gauge 16 blunt needle for n-heptane. A larger needle was used for n-heptane due to its lower surface tension. Measurements of the droplet weight showed a drop-todrop variation of less than $\pm 2 \%$. The droplets formed on the needle tip, and once large enough would detach under their own weight. Due to n-heptane's solvent characteristics, a glass syringe, along with stainless steel fittings and chemical resistant PVC tubing were used to prevent contamination of the working fluid.

The impact velocity was controlled by adjusting the vertical distance from the tip of the needle to the top of the substrate, and was fixed at $50 \pm 1 \mathrm{~mm}$ for the experiments. The impact velocities for the pure water and $n$-heptane droplets at the time of impact were $0.9 \mathrm{~m} / \mathrm{s}$. The velocity measurements were determined from high speed imaging where they varied by $\pm 5 \%$

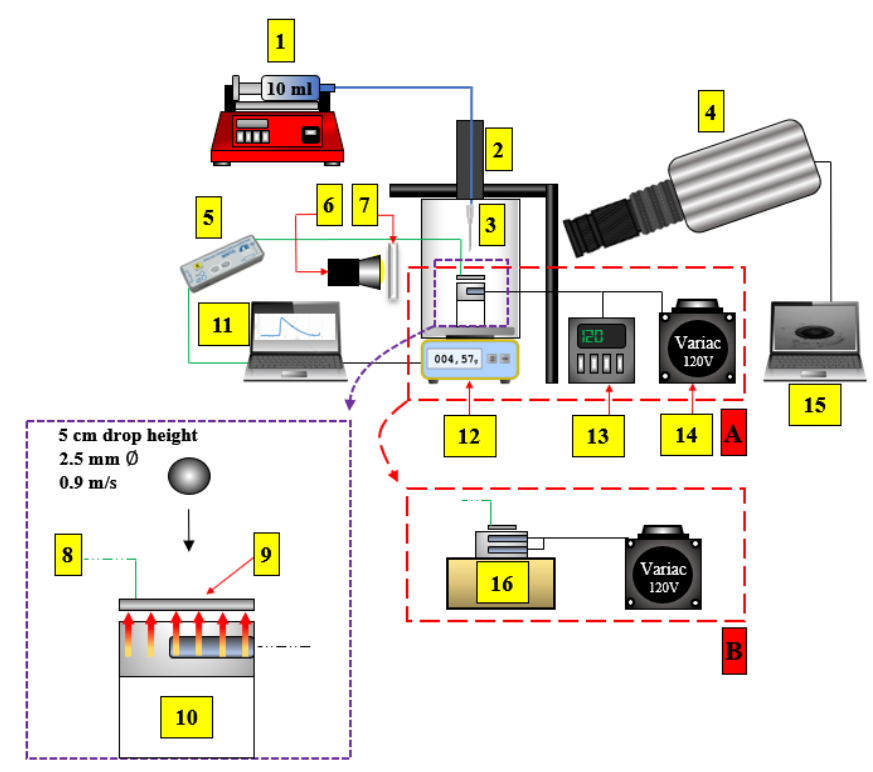

Figure 1. Schematic of experimental setup: (1) Syringe pump coupled with a $10 \mathrm{ml}$ syringe, (2) Vertical height adjustment, (3) Hypodermic needle, (4) Highspeed camera, (5) Wireless thermocouple connector, (6) Light source, (7) Light diffuser, (8) Thermocouple, (9) Substrate, (10) Thermal mass coupled with $100 \mathrm{~W}$ cartridge heater, (11) PC logging scale data, and monitoring substrate temperature, (12) Digital scale, (13) Temperature controller, (14) 120V Variac, (15) PC capturing high-speed camera images, (16) Thermal mass coupled with two, $200 \mathrm{~W}$ cartridge heaters. (a) Setup used at surface temperatures ranging from $60^{\circ} \mathrm{C}$ to $120^{\circ} \mathrm{C}$, (b) Setup used at surface temperatures above $120^{\circ} \mathrm{C}$.

for the water and $\pm 9 \%$ for the $\mathrm{n}$-heptane. The Weber numbers associated with these drop velocities are 29 and 65 respectively.

At surface temperatures ranging from $60^{\circ} \mathrm{C}$ to $120^{\circ} \mathrm{C}$, setup Fig. 1a was employed to capture droplet evaporation. A 3D printed plastic holder was created to hold an aluminum thermal mass ( $45 \mathrm{~mm}$ x $45 \mathrm{~mm}$ x $20 \mathrm{~mm}$ thick) in which the substrate would sit, and was heated using a single $100 \mathrm{~W}$ cartridge heater. The voltage applied to the heaters was adjusted with a $120 \mathrm{~V}$ variac and the substrate surface temperature was regulated using a temperature controller (CN9000A, Omega Engineering, Laval, Quebec, Canada) and could be controlled to $\pm 0.1^{\circ} \mathrm{C}$. Droplet evaporation was measured by placing the heated apparatus equipped with the surface on a digital scale (AG245, Mettler Toledo, Mississauga, Ontario, Canada) and recording the weight decrease as a function of time as the droplet evaporated.
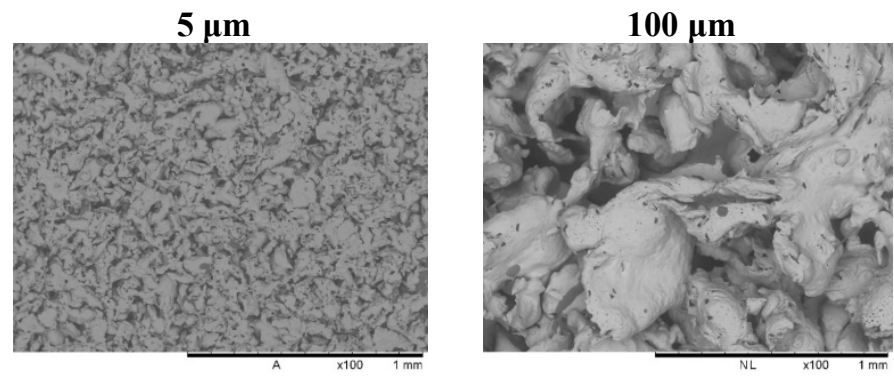

Figure 2. SEM images of the sintered porous stainless steel samples ( $5 \mu \mathrm{m}$ and $100 \mu \mathrm{m}$ average pore size) used during experimentation. Substrate dimensions: $45 \mathrm{~mm} \times 45 \mathrm{~mm}$ by $1.5 \mathrm{~mm}$ thick. 
With surface temperatures above $120^{\circ} \mathrm{C}$, due to limitations with the 3D printed polylactic acid (PLA) substrate holder having a maximum operating temperature of approximately $150^{\circ} \mathrm{C}[9]$, and the scale having a maximum sample rate of $3 \mathrm{~Hz}$, setup Fig. $1 \mathrm{~b}$ was employed. This setup used a larger aluminum thermal mass ( $70 \mathrm{~mm}$ wide x $75 \mathrm{~mm}$ long x $40 \mathrm{~mm}$ thick) equipped with two, $200 \mathrm{~W}$ cartridge heaters wired in parallel and powered by a $120 \mathrm{~V}$ variac used to regulate the heater output. The high-speed camera (Fastcam SA5, Photron, Tokyo, Japan) equipped with a bellows and $105 \mathrm{~mm}$ lens, was used to capture evaporation times at frame rates of 1000 to $5000 \mathrm{fps}$.

Surface temperatures of $150^{\circ} \mathrm{C}$ and above were in the nucleate boiling regime for both water and $n$-heptane, and evaporation was fast enough to prevent significant spreading of the absorbed liquid. As a result, the evaporation time of the deposited liquid coincided with the disappearance of the dry out front. All experiments were performed at an ambient room temperature of $23^{\circ} \mathrm{C} \pm 3^{\circ} \mathrm{C}$.

\section{RESULTS AND DISCUSSION}

The difference in evaporation times observed between the pure water and $\mathrm{n}$-heptane are closely tied to the differences in fluid properties and how that affects the behavior of the droplet as it impacts on the porous surfaces. Figs. 3 and 4 show image sequences of the first 25 milliseconds immediately after impact of pure water (Fig. 3) and n-heptane (Fig. 4) droplets impinging on (a) an impervious surface, (b) a surface with $5 \mu \mathrm{m}$ pores and (c) a surface with $100 \mu \mathrm{m}$ pores. The initial surface temperature in all cases was $250^{\circ} \mathrm{C}$. Droplets were deposited from a $50 \mathrm{~mm}$ drop height. The water and $\mathrm{n}$-heptane droplets evolution on all three surfaces starts off similar during the first $2.4 \mathrm{~ms}$ except for the spread factor which is larger with the n-heptane as compared to the water on the same surface due to n-heptane's lower surface tension. The spread factor $(\boldsymbol{\beta})$ is the dynamic spread diameter of the droplet after impact normalized by the initial droplet diameter $\left(\boldsymbol{\beta}_{\text {film }}=D_{\text {film }} / d_{0}\right)$. The lower surface tension allows inertial forces to play the dominant role during droplet impact where the formation of the liquid jet can span a larger distance before viscous dissipation, surface tension and surface roughness effects dissipate the kinetic energy and bring the droplet to a stop. The surface roughness can be seen impeding the droplet spread as porosity is increased with both water and $\mathrm{n}$-heptane. The water droplet begins its upwards levitation at 10 ms on the impermeable surface (see Fig. 3a) while this process is observed to be delayed with the n-heptane (see Fig. 4a). This appears to be due to n-heptane's larger contact area, where the droplet has a longer distance to recoil before levitation of the bulk fluid occurs. Similarly, instability at the rim of the lamella for n-heptane takes effect early in the spreading process at $1 \mathrm{~ms}$ for all three surfaces. The fingering is a source for satellite droplets which can be seen being ejected from the bulk of the fluid at 10 to $25 \mathrm{~ms}$. The Leidenfrost point (LP) was achieved with the water on the impervious surface only, and with the nheptane on all surfaces, porous and impervious. The delayed

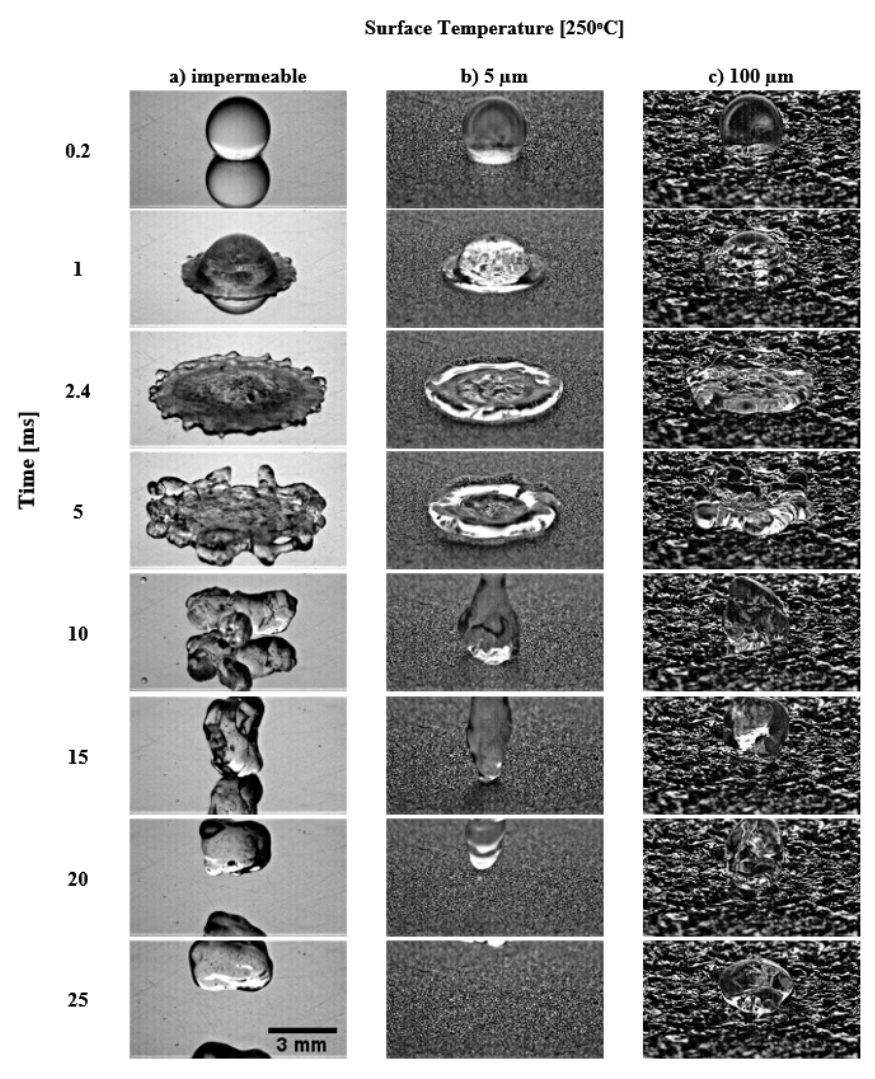

Figure 3. Water droplet impact on the (a) impermeable, (b) $5 \mu \mathrm{m}$ and (c) 100 $\mu \mathrm{m}$ surfaces. Surface temperature $\mathrm{Tw}=250^{\circ} \mathrm{C}$ (film boiling regime), $\mathrm{Vi}=0.9$ $\mathrm{m} / \mathrm{s} \pm 5 \%$, do $=2.5 \mathrm{~mm} \pm 2 \%$, We $=29$.

onset of the LP is due to the vapors produced during evaporation being able to permeate through the porous structure preventing vapor pressures from building between the solid-liquid interface, and allowing the fluid to remain in contact with the surface at increased temperatures. Direct contact heat transfer across a solid-liquid interface is higher than across a vapor gap improving the evaporation times in the film boiling regime. Droplet levitation occurred with the n-heptane on the porous surfaces due to its lower heat of vaporization. It takes less energy to cause a phase change, where the rate of vapor production as a result would increase. The pressures build underneath the droplet providing the necessary forces required for levitation.

Curves of the droplet lifetime as a function of surface temperature can be used to determine when changes occur during the evaporation and impact process [4]. For both pure water and $\mathrm{n}$-heptane, the droplet lifetime curves as a function of surface temperature followed similar trends and are shown in Figs. 5 and 6 respectively. A graph insert is shown in each of the plots, utilizing a log time scale to clearly illustrate the difference in evaporation times between the three surfaces at temperatures ranging from $150^{\circ} \mathrm{C}$ to $300^{\circ} \mathrm{C}$. As the surface temperature was raised, evaporation times decreased until a minimum was reached, corresponding to the critical heat flux (CHF) point. For pure water on the impervious and the $100 \mu \mathrm{m}$ surfaces, the CHF occurred at approximately $200^{\circ} \mathrm{C}$. The CHF for the $5 \mu \mathrm{m}$ surface occurred at $150^{\circ} \mathrm{C}$. Similarly, for the n-heptane the CHF for all 


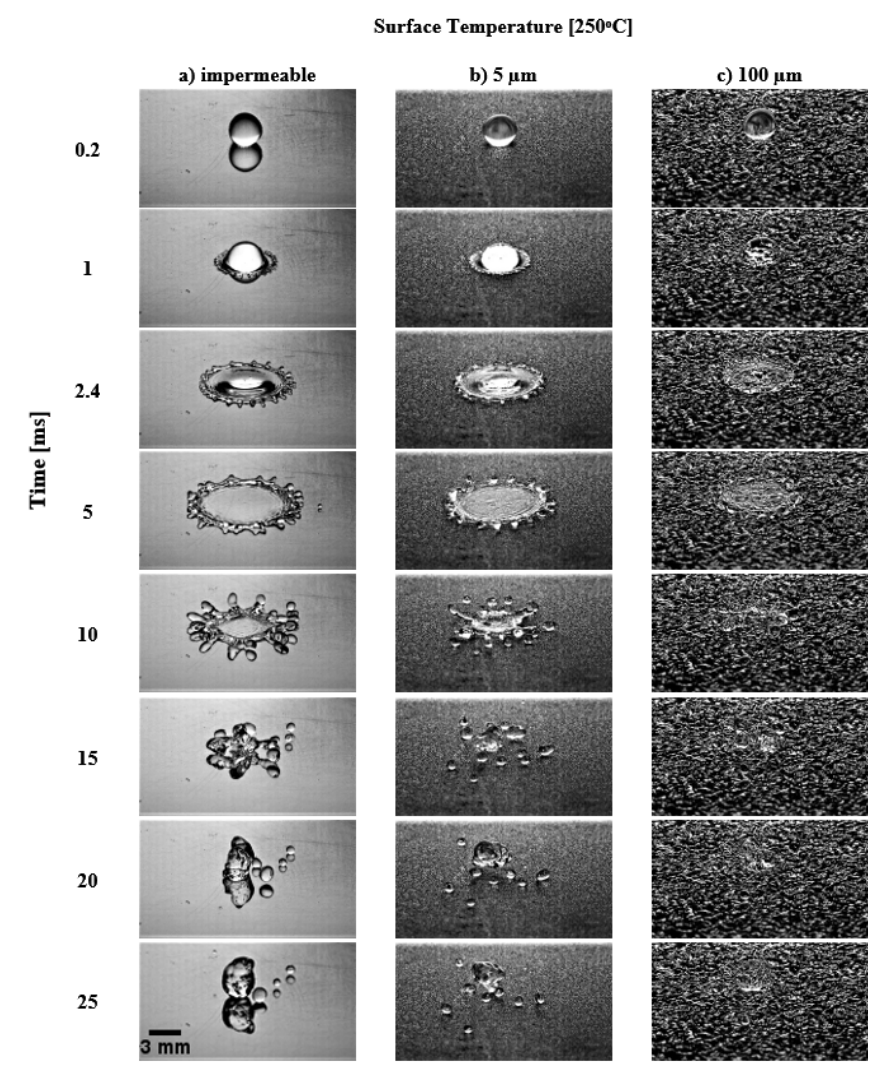

Figure 4. n-Heptane droplet impact on the (a) impermeable, (b) $5 \mu \mathrm{m}$ and (c) $100 \mu \mathrm{m}$ surfaces. Surface temperature $\mathrm{Tw}=250^{\circ} \mathrm{C}$ (film boiling regime), $\mathrm{Vi}=$ $0.9 \mathrm{~m} / \mathrm{s} \pm 9 \%$, do $=2.5 \mathrm{~mm} \pm 2 \%, \mathrm{We}=65$.

three surfaces happened at approximately $150^{\circ} \mathrm{C}$. At low wall temperatures ranging between $60^{\circ} \mathrm{C}$ to $120^{\circ} \mathrm{C}$ the ability of the porous substrates to effectively vaporize the water and $n$-heptane droplets displayed significantly different results. The water droplet evaporated the fastest on the $5 \mu \mathrm{m}$ surface while the nheptane droplet on average evaporated the slowest as compared with the impervious and $100 \mu \mathrm{m}$ surfaces. The reduced times

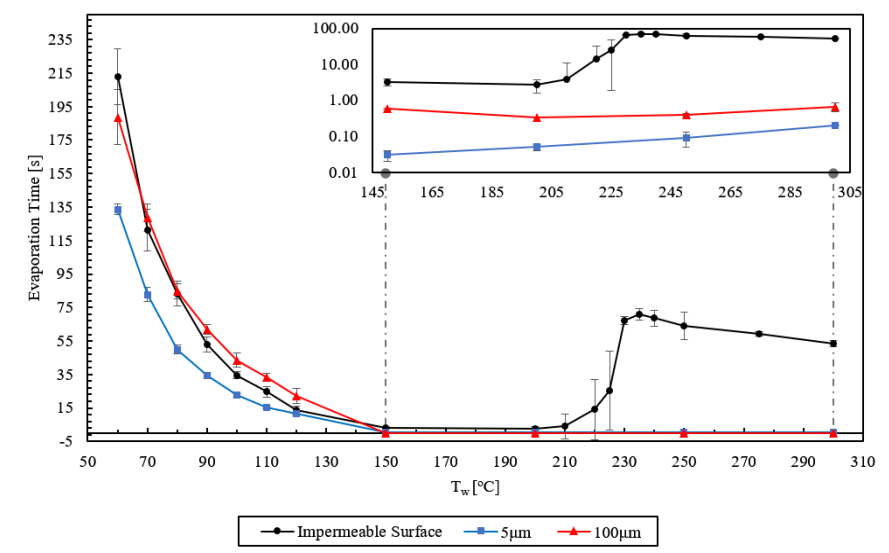

Figure 5. Evaporation time as a function of the surface temperature for the (a) impermeable, (b) $5 \mu \mathrm{m}$ and (c) $100 \mu \mathrm{m}$ surfaces using pure water as the working fluid. A graph insert is shown at surface temperatures ranging from $150^{\circ} \mathrm{C}$ to $300^{\circ} \mathrm{C}$ using a log time scale to show evaporation time differences between the surfaces.

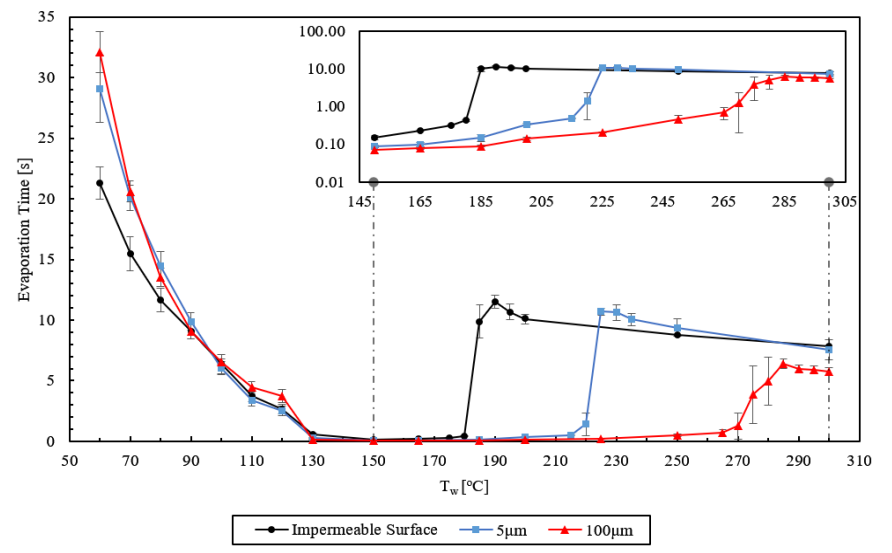

Figure 6. Evaporation time as a function of the surface temperature for the (a) impermeable, (b) $5 \mu \mathrm{m}$ and (c) $100 \mu \mathrm{m}$ surfaces using n-heptane as the working fluid. A graph insert is shown at surface temperatures ranging from $150^{\circ} \mathrm{C}$ to $300^{\circ} \mathrm{C}$ using a log time scale to show evaporation time differences between the surfaces.

with the water is attributed to an increase in the total contact area that can be achieved as the water permeates into the porous structure. As the primary mode of heat transfer within this temperature range is heat conduction, this would increase the rate of heat transfer to the fluid reducing overall evaporation times. Moreover, the increased evaporation times observed with the n-heptane can be attributed to the fluids lower surface tension. The reduction in surface tension substantially improves the rate at which n-heptane penetrates the surface pores causing the fluid to pool at the bottom of the substrate before fully evaporating. Due to n-heptane's low heat of vaporization and the lower permeability of the $5 \mu \mathrm{m}$ surface, vapor pressures build up more rapidly within the substrate, reducing heat transfer and increasing the time required for complete evaporation. Similar behavior can be observed with the water and n-heptane on the $100 \mu \mathrm{m}$ surface within this temperature range. As wall temperatures were raised, ranging from $150^{\circ} \mathrm{C}$ to $300^{\circ} \mathrm{C}$, the porous substrates were the most effective at vaporizing both the water and n-heptane droplets before the LP was reached. This behavior suggests that the substrate structure plays a critical role in droplet evaporation. Water droplets evaporated the quickest on the $5 \mu \mathrm{m}$ surface due again to an increased contact area that can be achieved as the vapors permeate away from the solidliquid interface allowing the droplet to remain in contact with the surface at the increased temperatures. Additionally, the nheptane evaporated the fastest on the $100 \mu \mathrm{m}$ surface. Due to the low heat of vaporization of $n$-heptane, and the higher porosity, and permeability of the $100 \mu \mathrm{m}$ surface compared to the $5 \mu \mathrm{m}$ surface meant a larger quantity of vapor could flow into the porous structure. As a result, less vapor will build up within the porous cavities hindering the rate of evaporation. The LP was reached with the water droplet on the impervious surface at $235^{\circ} \mathrm{C}$. Similarly, the LP was successfully reached with the nheptane at surface temperatures of $190^{\circ} \mathrm{C}$ (impervious surface), $225^{\circ} \mathrm{C}(5 \mu \mathrm{m}$ surface $)$, and $285^{\circ} \mathrm{C}$ (100 $\mu \mathrm{m}$ surface) respectively. 


\section{ACKNOWLEDGMENT}

The authors gratefully acknowledge funding for this project provided by the Natural Sciences and Engineering Research Council of Canada.

\section{REFERENCES}

[1] Bernardin, J.D., Stebbins, C.J., Mudawar, I., "Mapping of impact and heat transfer regimes of water drops impinging on a polished surface," Int. J. Heat Mass Transf., 40, pp. 247-267, (1997).

[2] Hapgood, K.P., Litster, J.D., Simon, S.R., Howes, T., "Drop penetration into porous powder beds," Journal of Colloid and Interface Science, 253, pp. 353-366, (2002).

[3] Avedisian, C.T., Koplik, J., "Leidenfrost boiling of methanol droplets on hot porous/ceramic surfaces," Int. J. Heat Mass Transf., 30(2), pp. 379393, (1987).

[4] Chandra, S., Avedisian, C.T., "Observations of droplet impingement on a ceramic porous surface," Int. J. Heat Mass Transf., 35(10), pp. 2377-2388, (1992).

[5] Abu-Zaid, M., "An experimental study of the evaporation of gasoline and diesel droplets on hot surfaces," International Communications in Heat and Mass Transfer, 21(2), pp. 315-322, (1994).

[6] Kim, W.S., Lee, S.Y., "Behavior of a water drop impinging on heated porous surfaces," Experimental Thermal and Fluid Science, 55, pp. 6270, (2014).

[7] Liang, G., Mudawar, I., "Review of drop impact on heated walls," International Journal of Heat and Mass Transfer, 106, pp. 103-126, (2016).

[8] Hu, H., Larson, R.G., "Evaporation of a sessile droplet on a substrate," J. Phys. Chem., 106, pp. 1334-1344, (2002).

[9] MakerBot, Safety Data Sheet (PLA 3D Printer Filament/ MakerBot PLA), Retrieved September 8, 2017, from https://images.makerbot.com/support/production/SDS-000002ENA.pdf. 